\title{
吉林陨石的天然剩磁和早期行星际 空间磁场强度的初步探讨
}

\author{
李华梅王俊达 \\ (中国科学院典阳地球化学研究所)
}

研究陨石的天然剩磁, 测定早期太阳系的磁场强度, 对于人们了解地球和行星的起源与演 化有着重要的意义. 最近, 我们通过对吉林陨石的磁性分析, 提出 42 亿年前行星际空间磁场 强度比现在高上万倍的初步认识. 本文就是这一研究结果的简要报道.

\section{方法}

吉林陨石属檄榄石一古铜辉石球粒陨石类型[1]. 其中磁性矿物以铁镍合金及陨硫铁为主, 此外还含有铬铁矿和铁铁矿等。铁镍合金由铁纹石 (90-95\%) 和镍纹石 (5-10\%) 组成. 上 述矿物是在太阳星云的凝聚过程中形成的,并且,此后还经过了热变质作用.

实验证明 ${ }^{[2,3]}$ ，含铁磁性矿物的岩石，在弱磁场中从高温冷却到居里点以下即可获得热剩 余磁化强度. 热剩余磁化强度的特征之一是它的大小与外磁场强度成正比, 并且磁性稳定. 另 一个基本性质是它的加法性, 即铁磁性物质从居里温度冷却到室温所获得热剩余磁化强度, 等 于居里点以下各温度间隔所得的部分热剩余磁化强度的总和, 并且每个温度间隔得到的部分 热剩磁又是相互独立的. 根据上述两个基本规律，借助于各个温度间隔中退掉的天然热剩余 磁化强度和已知磁场 $H$ 中所获得的热剩余磁化强度 $I_{t}$ 的比较, 就能确定古代磁场强度 $H_{a}{ }^{[4]}$.

我们将“吉林 1 号”和 “G65 号” 陨石切成 11 块 $2 \times 2 \times 2$ 立方厘米的小立方体作为测量 分析样品. 磁性测量采用国产 WCWI-63 型小无定向磁力仪, 其灵敏度为 $5.4 \times 10^{-6}$ 奥斯特/ 衰米.热退磁设备是由自制的无磁感应电热妒和无磁场空间组成.样品冷却的无磁场空间是由 两对相互垂直的赫姆霍兹线圈和双层坡莫合金的屏蔽来实现的. 热退磁和热磁化运用了两种 方法: 一种是把样品置于妒中加热到某一温度后, 放在无磁场空间冷却退磁, 后又加热到同一 温度, 再置于地磁场中冷却磁化; 另一种方法是把样品加热到某一温度后, 顺地磁场冷却磁化, 然后再将样品加热到同一温度后, 逆地磁场冷却磁化. 样品在所要求的温度下恒温一小时, 冷 却 5 小时. 为了防止样品在加热过程中发生篻化, 设有专门装置不断地给样品充以中性气体.

为了检验样品的磁稳定性, 用一块样品进行了系统的交变退磁试验,结果发现交变磁场峰 值达到 100 奥斯特时，其天然剩余磁性衰减到小于原值的 $10 \%$ ，说明吉林陨石中含有较多的 软磁组分. 

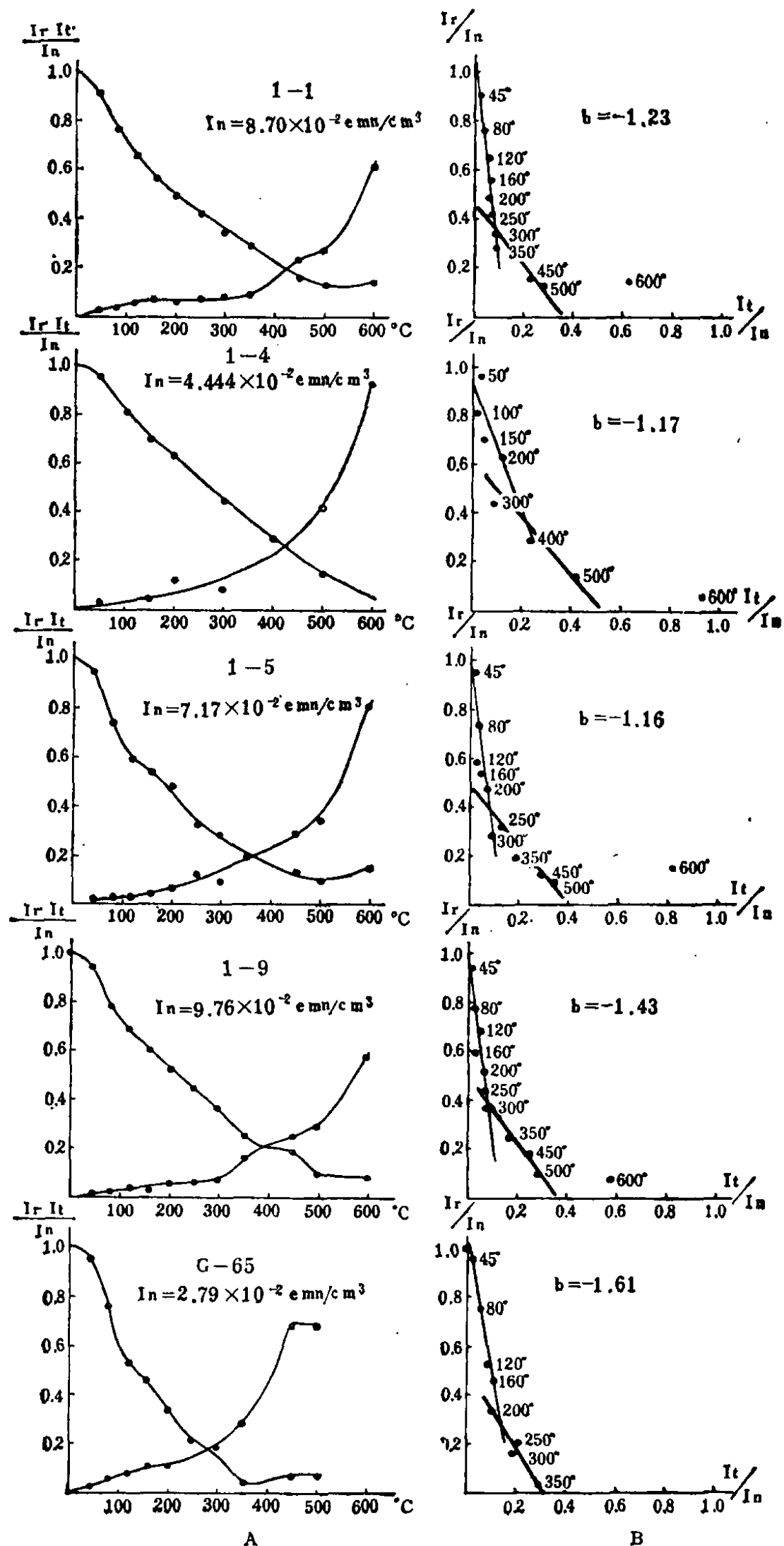

图 1

A一一陨石样品的热退磁曲线和在 0.47 奥斯特磁场中的热磁化曲线。 In 是样 品的天然剩余磁化强度； $\mathrm{B}$ 一一天然剩磁的部分热退磁强度与部分热磁化强 度的比. b 是 $250(200)-500^{\circ} \mathrm{C}$ 各温度点的直线斜金. 黑点上的数字为 ${ }^{\circ} \mathrm{C}$ 


\section{结·果}

一、对 11 块吉林陨石样品的测量，我们得到了如下几个基本数据:

1. 吉林陨石的天然剩余磁化强度 $I_{n}$ 值的范围是 1.07一9.76 $\times 10^{-2}$ 高斯, 平均值为 $4.41 \times$ $10^{-2}$ 高斯.

2. 在 0.25 奥斯特磁化磁场中得到的磁化率 $K$ 值的范围是 $1.56-1.89 \times 10^{-1}$, 平均值 $1.68 \times$ $10^{-1}$. 样品各方向上磁化率 $K$ 的最大值和最小值之比代表磁各向异性度 $P$, 其范围 是 1.21.7 .

3. 天然剩磁 $I_{n}$ 与地磁场中所获得的感应磁化强度 $I_{i}$ 的比值 $Q$ 平均为 1.5 .

二、样品热磁分析的两个结果:

1. 吉林陨石的居里温度：从热退磁曲线上 (图 1), 我们得到的吉林 1 号陨石的居里温度 是500-600 ${ }^{\circ} \mathrm{C}, \mathrm{G} 65$ 号陨石的居里点是 $350-400^{\circ} \mathrm{C}$.

2. 吉林陨石的古磁场强度: 图 1A 是 5 块陨石样品的天然剩余磁化强度的热退磁曲线和 在 0.47 奥斯特磁场中的热磁化曲线. 各温度点保留的天然剩磁值与对应的所获得的热磁化强 度值表示在图 1B 上, 各温度点之间应是线性关系, 并且其斜率就是古磁场强度和已知磁化磁 场强度的比值. 图 1B 中有两条斜率不同的直线, $250^{\circ} \mathrm{C}$ (或 $200^{\circ} \mathrm{C}$ ) 以下的直线斜率相当大, 平均为 5.5. $250^{\circ} \mathrm{C}$ (或 $200^{\circ} \mathrm{C}$ ) - $500^{\circ} \mathrm{C}$ (或 $350^{\circ} \mathrm{C}$ ) 温度区间的直线斜率范围是 $1.16-1.61$, 平 均为 1.25 .

考虑到: (1)吉林陨石含有较多的不稳定的磁性组分, 容易获得等温剩磁和粘滞磁化强度 等次生成分以及样品重新加热的次生热剩磁, $250^{\circ} \mathrm{C}\left(200^{\circ} \mathrm{C}\right)$ 以下的不能代表陨石形成时代的 原始磁场;(2)吉林陨石主要铁磁性成分的铁一镍合金中,镍的重量百分比是 $8.73 \%$ 。据实验资 料 ${ }^{[5]}$, 镍的含量在 $8.73 \%$ 的铁镍合金由 $\alpha-\mathrm{Fe}$ 转变成 $\gamma-\mathrm{Fe}$ 时的相变温度约为 $720^{\circ} \mathrm{C}$. 因此, 对 于居里点为 $500-600^{\circ} \mathrm{C}$ 的 1 号陨石我们采用了 $250-500^{\circ} \mathrm{C}$ 这一温度区间的结果, 而居里点 为 $350-400^{\circ} \mathrm{C}$ 的 $\mathrm{G} 65$ 号样品我们则采用了 $200-350^{\circ} \mathrm{C}$ 这一温度区间的直线斜率. 由此而算 得的吉林陨石的古磁场强度平均值应为 0.59 奥斯特.

\section{讨 论}

一、我国吉林陨石的磁性特点之一是它具有较低的居里温度. 近年来, 世界各国已研究 过的一些陨石, 其居里温度一般在 $700-800^{\circ} \mathrm{C}$, 而吉林陨石居里温度多在 $500-600^{\circ} \mathrm{C}$, 是相 对较低的. 导致这一差异的原因, 可能与吉林陨石的镍含量较高有关. 吉林陨石中铁镍合金 含量为 $19.7 \%$,而镍在铁镍合金中占 $8.73 \%$ 。据 5 块铁纹石样品经电子探针分析结果表明,主 要铁磁矿物的铁纹石中瀪的平均含量也高达 $7.84 \%$, 而在镍纹石中镍的含量可达 $30-50 \%$ 。

二、吉林陨石经历了从太阳星云凝聚形成母体, 热变质和破裂三个阶段 ${ }^{[1]}$. 其中热变质 阶段温度高达约 $1000^{\circ} \mathrm{K}$, 而吉林陨石的居里点最高为 $650^{\circ} \mathrm{C}$, 可见,吉林陨石的天然剩磁最大 可能是在母体热变质阶段所获得的热剩磁,距今约有 42 亿年.

三、在现代地磁场强度为 0.47 奥斯特的实验条件下,得到的磁场比值为 $1.16-1.61$, 平均 为 1.25. 根据这一比值计算出陨石形成时磁化的外磁场为 0.59 奥斯特. 近年来, 美国、日本 
等一些国家,所测得的陨石外磁场强度在 0.1一-1.2 奥斯特范围内. 如艾伦德 (Allende) 陨石为 1.09 奥斯特,默奇森 (Murchison) 陨石为 0.18 奥斯特, 奥奎尔(Orgueil)陨石为 0.67 奥斯特 ${ }^{[6]}$, 塞 米洛尔 (Seminole) 陨石为 0.39 奥斯特, 以及多格蒂唐斯 (Dalgety Downs) 陨石为 0.68 奥斯特 ${ }^{[7]}$, 等等. 由此看来,从星际空间註落到地球的陨石,其外磁场强度是比较相近的.

四、吉林陨石主要可能是近火星来源的. 根据目前资料 ${ }^{[8]}$, 现在行星际空间磁场强度正 常值约 3-6 伽玛 ( $\gamma=10^{-5}$ 奥斯特), 火星和金星的赤道处磁场强度 $\leqslant 60$ 伽玛, 月球表面偶 极子场只有 1.5-3 伽玛. 至今发现的太阳系中磁场较大的水星也不超过 350 伽圪 (赤道) 一 700 伽玛 (两极). 吉林陨石磁性研究的结果表明, 42 亿年前, 行星际空间曾经存在过较强的 磁场, 其强度约为 59000 伽玛, 比现在行星际空间磁场要大上万倍.

本文承欧阳自远同志提出许多宝贵意见. 文中还引用了战新志和戴逢福、朱永煊同志有关陌石中铁磁 生矿物和铁镍含量的数据. 在此一并致谢.

\section{龺文献}

[1] 中国科学院吉林陨石雨联合考察组, 中国科学, 1977, 1, 38 .

[2] 小峰稔、小暗都子, 岩石磁风学, 1972.

[ 3 ] Nagata, T., Rock Magnetism (Revised edition), Maruzen Tokyo, 1961, 145-165.

[4] 河野長, 科学, 45 (1975), 2, 101-109.

[5] Butler, R. F., Earth Planet. Sci. Lett., 17(1972), 120-128.

[ 6 ] Banerjee, S. K. \& Hargrayes, R. B., Earth Planet. Sci. Lett., $17(1972), 110-119$.

[7] Nagata, T. \& Sugiura, N., Phys. Earth Planet. Inter., 13(1977), 4, 373-379.

[ 8 ] Wasson, J. T., Meteorites Classification and Properties, Springer-Verlag, Berlin, Heidelberg, New York, 1974, 169-194.

\section{[上接 171 页]}

同位素演化图上可以构成一条直线 (图 2). 这表明了 $\mathrm{H}$ 群陨石母体几乎在 $4.7 \times 10^{9}$ 年左右 的同一时间内从太阳系星云中凝聚出来, 并且有很相近的 $\mathrm{Rb} / \mathrm{Sr}$ 比值.

由此, 可以得出以下两点结论:

1. 吉林球粒陨石母体约在 $4.7 \times 10^{9}$ 年前左右从太阳系星云中凝聚出来, 到 $4.5 \times 10^{9}$ 年 前左右发生过导致锶同位素均一化作用的变质事件.

2. 所有 $\mathrm{H}$ 群陨石的母体大约是在 $4.7 \times 10^{9}$ 年前的一个暂短时间间隔内从太阳星云中分异 出来的. 在太阳系早期的历史阶段内,每一陨石母体可能都有各自的演化历史,它们经历了不 同的时间间隔以后,才最后冷却并固结成为锶同位素均一化的封闭体系.

样品由本所选矿实验室陈建隆同志协助分选; 同位亲质谱分析由云南省地质科学研究所钩一锶年䊏实 验 室协助完成;朱炳泉同志对本工作提出过宝贵的意见,特此表示感谢.

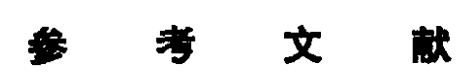

[1] 中国科学院吉林陌石雨联合考察组,地球化学, 1976, 2, 158 .

[2] Kaushal, S. K., Wetherill, G. W., J. Geophys. Res., 74 (1969), 2717-2726.

[ 3 ] Wasserburg, G. ]., Papanastassiou, D. A., Sanz, H. G., Earth Planet. Sci. Letters, 1969, 7, $33-43$.

[4] York, D., Can. J. Phys., 44 (1966), 1079-1086.

[5] Papanastassiou, D. A., Wasserburg, G. J., Earth Planet. Sci. Letters, 1969, 5, 361-376. 